Original Article

\title{
KNOWLEDGE REGARDING RCH SERVICES AM ONG HEALTH WORKERS, PREGNANT MOTHERS AND ADOLESCENTS IN RURAL FIELD PRACTICE AREA
}

\author{
Anusha Rashmi ${ }^{1}$, Rashmi \& N. Udaya Kiran ${ }^{3}$ \\ Post Graduate Student ${ }^{1}$, Associate Professor ${ }^{2}$, Professor \& Head $^{3}$, \\ Department of Community Medicine, K.S. Hegde Medical Academy, \\ Nitte University, Mangalore - 575018 \\ Correspondence: \\ Anusha Rashmi \\ E-mail : anurash7@gmail.com
}

\section{Abstract:}

Maternal mortality and morbidity are significant health problems in developing countries .Improving maternal health has been an essential element for achieving health for all and has been included in M DG to be achieved by 2010. Apart from mothers and children, the health of adolescents came into light as one of the important area mainly because of their role as future or immediate mothers. Role of health care providers especially the grass root level workers becomes particularly important not just in imparting the intending services, but also in imparting knowledge about reproductive health.

To assess the knowledge about RCH services among the health care workers, pregnant women, mothers and adolescent girls.

A cross sectional study was conducted in the rural field practice areas of K. S. Hegde M edical Academy. A total of 37 health workers, 50 pregnant women and mothers and 56 adolescents were interviewed using a pre tested questionnaire for assessing their knowledge regarding RCH services. Descriptive statistics was used in the analysis.

Knowledge regarding high risk pregnancy identification, normal birth weight and identifying anaemia in the field was good among health workers. Only $10.8 \%$ of them knew the minimum strength of medical officers in a FRU and only $5.4 \%$ knew about fast breathing in less than 2 months old infant. With regard to mothers knowledge $64 \%$ were aware of the number of ANC visits, $44 \%$ knew about correct interval between 2 pregnancies, 38\% knew about methods to prevent STI transmission. 82\% of adolescents had good knowledge regarding legal age for marriage. $75 \%$ were aware of various methods of contraception.

Keywords: RCH, Health workers, Pregnant mothers, Adolescent girls.

\section{Introduction:}

The ICPD defines reproductive health as 'a state of complete physical, mental and social well-being in all matters relating to the reproductive system and to its functions and processes.' Implicit in this is the right of men and women to be informed and to have access to safe, effective, affordable and acceptable methods of family planning of their and the right of access to health care

Access this article online Quick Response Code

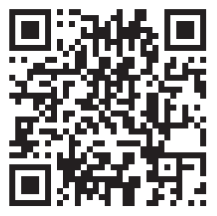

services that will enable women to go safely through pregnancy and childbirth. ${ }^{1}$

With the introduction of NRHM, the delivery of services to the community has become client centred, demand driven approach. For this purpose, sub centres and PHC's which form the main portal of $1^{\text {st }}$ contact as health facility in rural India have been improvised. Health care workers act as a main link between the community and the primary health care facilities. Thus the role of health care providers, especially grass root level workers becomes important not just in imparting the intending services but also in imparting knowledge about reproductive health.

Maternal health care package of antenatal care is the main programme of NRHM to strengthen RCH care. Antenatal care is a systematic supervision of women during pregnancy to monitor the progress of foetal growth and to ascertain the well being of mother and foetus. As a provider of ANC, health workers must ensure a healthy 
outcome for the mother and her baby. In Karnataka ANC coverage is reasonably good with $90.2 \%$ of women receiving any ANC irrespective of their background. ${ }^{2,3}$

An integrated agenda of NRHM is to promote awareness and knowledge of RTI/STI and HIV/AIDS and make health facilities accessible for diagnosis and treatment seeking to ensure healthy sexual life free from fatal infections. It is the responsibility of the health personnel to provide correct knowledge of RTI/STI, HIV/AIDS and to encourage prevention and treatment. According to the DLHS data in Dakshina Kannada, the awareness about RTI/STI is $73.9 \%{ }^{3}$

The public health also faces challenges with regards to adolescent health who constitute $18-25 \%$ of population in member countries in South-East Asia Region. ${ }^{4}$ Pregnancy, excess risk of maternal and infant mortality, ST/RTI, rapidly rising incidence of HIV in this group are some of the major concerns. Hence it is important to influence health seeking behaviour of adolescents as their situation will be central in determining the country's health. Addressing the adolescents will yield dividends in terms of delaying marriage, reducing incidence of teenage pregnancy, prevention and management of obstetric complications including access to early and safe abortion services and reduction of unsafe sexual behaviour. ${ }^{5}$

Hence, the present study was undertaken with the following objective to study the knowledge regarding $\mathrm{RCH}$ services among health workers (ASHA's, anganwadi workers), pregnant mothers and adolescent girls.

\section{Materialsand Methods:}

A cross sectional study was carried out in the rural field practice areas of K.S. Hegde M edical Academy, Deralakatte. Health care workers (ASHA's, anganwadi workers), antenatal mothers and adolescent girls formed our study subjects. The study subjects were administered the questionnaire during the group meetings held at the health centres respectively. The study sites were Natekal PHC, NITTE CHC and Muki CHC which were selected by convenience. A total of 37 health care workers, 50 antenatal mothers, 56 adolescent girls were selected by universal sampling. After reviewing appropriate literature a pre-tested validated questionnaire was made.

Each of the 3 study groups were given 3 different questionnaire which contained multiple choice questions and close ended questions. For the health workers questions were based on IPHS standards. Questions on basic must know knowledge regarding reproductive and child health were included for pregnant mothers and the adolescents. Questions were introduced by interview method. The questions were given weighted scores and the final knowledge score was calculated. Certain common questions were included in all the 3 questionnaires. All study subjects were clearly told about the purpose of the study and a written consent was obtained from them. The study was carried out over a period of one month (June 1 July 1, 2012). The data entry and analysis was done using Microsoft excel 2007. The results were expressed as percentage of number of subjects with correct responses.

\section{Results:}

Certain common questions were asked to all the 3 groups and their results are shown in Figure 1. The health workers had good knowledge which varied from $94 \%$ to $100 \%$. Knowledge of pregnant women varied from $44 \%$ to $100 \%$ and that of adolescents varied from $44 \%$ to $96 \%$. With regards to questions that were exclusively asked to the pregnant women and the adolescent the pregnant women had good knowledge (72\%) regarding fluids to be given to the child in case of loose stools while it was poor (18\%) knew about the vaccines to be given to the baby in neonatal period. The adolescents had a good knowledge (75\%) regarding the various method contraception. Figure 2 shows the percentage of health workers and pregnant women who answered correctly to common questions that were asked to them.

The health workers were asked questions in accordance to the IPHS standards and the results are shown in Table 1. The health workers knowledge regarding birth weight, anemia and J anani Suraksha Yojna was good (100\%, 97.2\%, $86.4 \%$ respectively). The knowledge score for each of the 3 groups was calculated separately. Scores from the 
individual questions were added up to calculate the final scores which are shown in Table 2.

\section{Discussion :}

The National Rural Health M ission (NRHM) foundation is built on community involvement in

drawing a village health plan under the auspices of Village Health \& Sanitation Committee

(VHSC), making rural primary health care services accountable to the community and giving authority to the District Health Mission for implementation of intersectoral District Health Plan including drinking water, sanitation, hygiene and nutrition. The interface between the community and the public health system at the village level is entrusted to a female Accredited Social Health

Activist (ASHA), a health volunteer receiving performance based compensation for promotion of universal immunization, referral and escort services for reproductive $\&$ child health (RCH), construction of household toilets, and other health care delivery programmes. To promote institutional delivery, cash incentive programme under Janani Suraksha Yojana (JSY) is made an integral component of NRHM . ANC provided by a doctor, an ANM or other health professionals comprises of physical checks, checking the position and the growth of foetus and giving TT injection at periodic intervals during the time of pregnancy. At least three check-ups are expected to complete the course of ANC to safeguard women from pregnancy related complications. ${ }^{2}$

In our study we found that the knowledge of health workers was better wherein $81 \%$ of the health workers were able to enumerate all criteria's of high risk pregnancy, $100 \%$ knew about the tablets to be taken during pregnancy, $86.4 \%$ knew about JSY. These findings were better as compared to a study done among health workers in Jamnagar district ${ }^{6}$ where only $71.56 \%$ were able to enumerate at least 5 criteria of at-risk mothers, $47.71 \%$ knew about the strength and dose of IFA tablets, $80.73 \%$ knew about JSY and its beneficiaries. In our study the knowledge of health workers with regards to antenatal checkups was good being $81 \%, 100 \%$ of them had correct knowledge regarding $\Pi T$ injections. $64.8 \%$ of them knew about MTP which was better than the study done in Gujarat ${ }^{7}$ which showed that though $95.2 \%$ of the health workers had correct knowledge about ANC visits and $93.7 \%$ of them knew about the number of TT injections to be taken, only $33.3 \%$ of them knew about MTP.

In this study about $56.96 \%$ had correct knowledge about prevention of STD while another study ${ }^{8}$ showed that only $19.43 \%$ among 243 girls had a correct knowledge of contraception. M ost of the girls were ignorant about STD. Our study shows that $82 \%$ of the adolescents knew about the legal age for marriage while another study ${ }^{9}$ showed that though the girls were aware that there was a minimum age for marriage only $65 \%$ could accurately define the age as 18yrs of age. The better knowledge among the adolescents in our study as compared to the others could be attributed to the ARSH programs that are running in the health centers. Also the literacy status is higher in Dakshina Kannada as compared to the northern states. This could be another factor contributing to higher level of knowledge among the adolescents in our study. Regarding menstrual hygiene only $55.18 \%$ of the adolescents in our study knew about the regularity of changing pads which was just average as compared to another study ${ }^{10}$ which showed that $97.8 \%$ of them knew about sanitary napkin/clean cloth to be used during menses and changed regularly. This shows that there are certain areas in personal hygiene which may not have been properly communicated to the adolescents.

With regards to pregnant mothers our study showed that an average of $62.3 \%$ were aware of ANC services, though the overall knowledge regarding RCH services among pregnant women was $53.2 \%$ which was less than a study done among 2 tribals ${ }^{11}$ which showed that $83.78 \%$ were aware of ANC services. $9.46 \%$ gave a history of inadequate utilization of ANC services because of inappropriate advice from health workers.. Previous studies show that illiteracy, increasing age and poor socio economic status, increasing birth order have an effect on ANC and that utilization of services was more where there was associated medical 
problems and lack of awareness about the available services was one of the reasons for non utilization. ${ }^{12,13,14}$ This emphasizes the need for education to increase the awareness and utilization of services by the community.

While calculating the overall knowledge scores we found that the health workers had good knowledge (78\%) as compared to the pregnant women $(54.8 \%)$ and adolescents (53.2\%). Also with regard to questions that were asked to health workers and the pregnant women only, the health workers knowledge was better. These findings show that though that there is a knowledge dissemination gap from the health workers to the community.

\section{Conclusion :}

The health workers knowledge regarding the $\mathrm{RCH}$ services was good while that for the pregnant mothers and the adolescents it was average. This shows that there is need to conduct more training programmes for the health workers to better their knowledge and also educate them about the importance of informing the community regarding the $\mathrm{RCH}$ services. There is also a need to conduct more health education programmes for adolescent girls and women about various aspects of reproductive health and the services available.

\section{Limitations of the Study:}

The sample that was taken in this study may not be representative of the population as only those who attended the clinic were taken into consideration. Also this study did not take into consideration the socio demographic status of the study subjects which would have given more insights to the factors contributing to their knowledge. Also the health workers years of experience was not taken into account which again plays an important role in the knowledge level. This study also did not take into consideration the gravid status of the pregnant women which would be a contributing factor to the knowledge in women regarding services available.

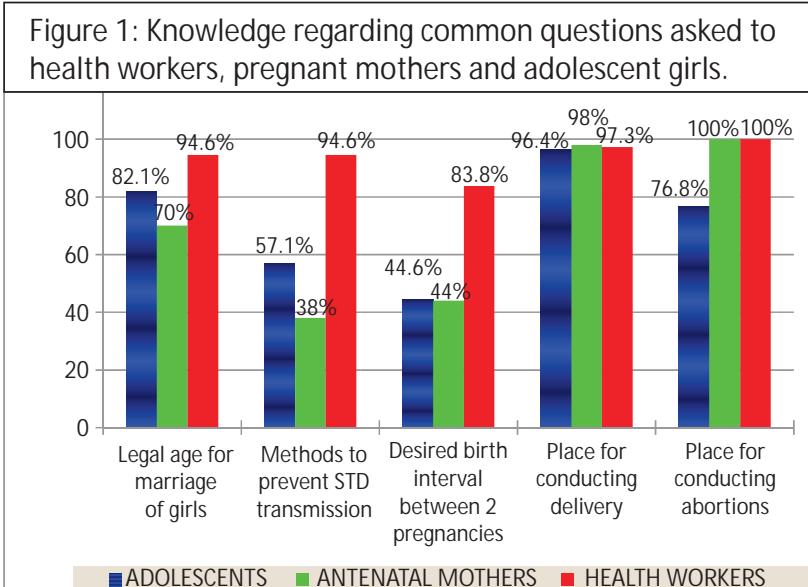

Figure 2: No of health workers and pregnant mothers who answered correctly to certain common questions ( in percentage)

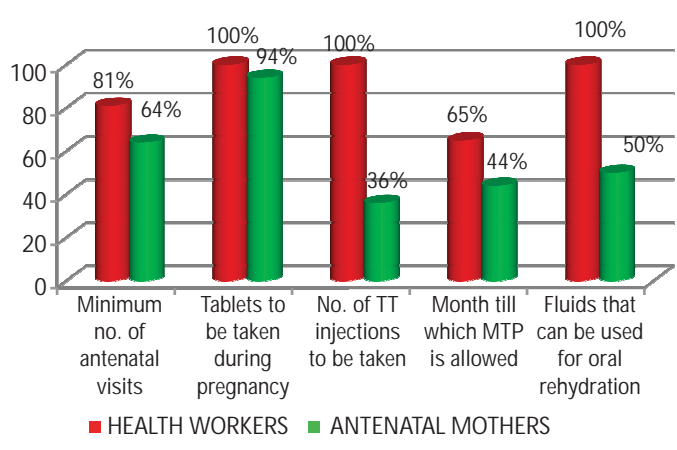

Table 1: Knowledge regarding questions asked exclusively to health workers $(n=37)$

\begin{tabular}{|l|c|c|}
\hline QUESTIONS & $\begin{array}{c}\text { AWARE } \\
\text { (in percentage) }\end{array}$ & $\begin{array}{c}\text { UNAWARE } \\
\text { (in percentage) }\end{array}$ \\
\hline $\begin{array}{l}\text { 1) M inimum strength of M O } \\
\text { in FRU }\end{array}$ & $10.8 \%$ & $89.1 \%$ \\
\hline $\begin{array}{l}\text { 2) Whether PHC is a FRU } \\
\text { or not }\end{array}$ & $54 \%$ & $45.9 \%$ \\
\hline $\begin{array}{l}\text { 3) Normal birth weight } \\
\text { in India }\end{array}$ & $100 \%$ & $2.8 \%$ \\
\hline $\begin{array}{l}\text { 4) Advice to prevent and } \\
\text { treat anaemia }\end{array}$ & $97.2 \%$ & $13.6 \%$ \\
\hline $\begin{array}{l}\text { 5) What is Janani Suraksha } \\
\text { Yojna }\end{array}$ & $86.4 \%$ & $94.6 \%$ \\
\hline $\begin{array}{l}\text { 6) Fast breathing in infants } \\
\text { less than 2 months }\end{array}$ & $5.4 \%$ & \\
\hline
\end{tabular}

\begin{tabular}{|c|c|c|c|}
\hline \begin{tabular}{|l} 
SUBJECTS \\
\end{tabular} & SUBJECT SCOR: & TOTAL SCORE & PERCENTAGE \\
\hline Health workers & 1327 & 1702 & $78 \%$ \\
\hline Pregnant women & 712 & 1300 & $54.8 \%$ \\
\hline Adolescents & 417 & 784 & $53.2 \%$ \\
\hline
\end{tabular}




\section{References:}

1. International Conference on Population and Development ICPD'94. Summary on progress of action Chapter 7 'Reproductive Rights and Reproductive health'

2. International Institute for Population Sciences (IIPS),2010: District level household survey (DLHS-3), 2007-08: India, Karnataka: Mumbai:IIPS.

3. Guidelines for antenatal care and skilled attendance at birth by ANM s/LHVs/SNs' Maternal health division MOHFW Government of India 2010.

4. Adolescence health and development'available from www.searo.who.int last accessed on September 12, 2012

5. 'Adolescent Reproductive and Sexual Health (ARSH) Strategy under NRHM / RCH-II' available from mohfw.nic.in last accessed on September 12, 2012

6. Kaushik Lodhiya K, Pradeep Pithadiya R, Raman Damor D, Sumit Unadkat V, Sudha Yadav B .A study of knowledge and skills of female health workers regarding maternal care under $\mathrm{RCH}$ programme. National Journal of Community Medicine Vol 3 Issue 1 Jan-March 2012.

7. Naresh R M akhwana, Viral R Shah, Sudha Yadav. An evaluation of skill and knowledge in delivery of reproductive and child health services by female health workers in Jamnagar district and corporation area, Gujarat state, India. International Journal of Health and Allied sciences
Vol 1 Issue 2 Apr-Jun 2012.

8. Ratna M ajumdar and S.K. Ganguli . A study of adolescent girls in Pune. Health and Population- Perspectives and Issues 23(2): 95-104, 2000

9. D. Pattanaik, J. Lobo, S. K. Kapoor, P. S. N. Menon .Knowledge and attitudes of rural adolescent girls regarding reproductive health issues. The National M edical Journal of India 2000 Vol13, No.3, 2000

10. K. M alleshappa, Shivaram Krishna, Nandini C. Knowledge and attitude about reproductive health among rural adolescent girls in Kuppam mandal: An intervention study. Biomedical Research 2011; 22 (3): 305-310

11. Mumbare SS, Rege R. Antenatal care service utilization, delivery practices and factors affecting them in tribal area of North M aharashtra. Indian J Community M ed 2011;36:287-90

12. Prabir Kumar Manna, Debasis De and Debidas Ghosh . Knowledge attitude and practices for antenatal care and delivery of the mothers of tea garden in Jalpaiguri and Darjeeling districts, westbengal. National Journal of Community M edicine 2011 Volume 2 Issue 1

13. Agarwal P, Singh M M, Garg S. M aternal health-care utilization among women in an urban slum in Delhi. Indian J Community Med 2007:32:203-5

14. M anish K Singh, J V Singh, N Ahmad, Reema Kumari, A Kanna. Factors affecting utilization of ASHA services under NRHM in relation to maternal health in Lucknow. Indian J Community M ed 2010;35:414-19 